\title{
Research Square \\ Addiction Therapeutic communities: residents' retention, early dropout, and their correlates over fourteen years
}

Abdulaziz T Alshomrani ( $\sim$ azsham@hotmail.com )

College of Medicine at Al-Imam Muhammad Ibn Saud Islamic University

Primary research

Keywords: ATCs, TC 1, TC 2, physical, psychological, social health

Posted Date: December 4th, 2020

DOI: https://doi.org/10.21203/rs.3.rs-120410/v1

License: (c) (i) This work is licensed under a Creative Commons Attribution 4.0 International License.

Read Full License 


\section{Abstract \\ Background}

Long-term retention is a reliably well-studied factor associated with enhanced outcomes in addiction therapeutic communities (ATCs). Staying no less than three months is considered to be a critical time for program effectiveness. I plan to estimate retention rates of Saudi AATCs for three months, completion of therapy (stay at least six months), and early abandonment and investigate its correlations in this study.

\section{Methods}

A cohort retrospective study where data of all residents admitted to all Saudi ATCs since their establishment in 2000 through September 2014 were collected from their AATCs files. At the time of the study, there were five AATCs, two of them in Dammam, one in Riyadh, one in Jeddah, and the fifth one was in Taif. Date of admission, date of discharge, socio-demographic variable, and type of drug used of all of the five ACS were reported. Retention rate at 3 and 6 months and dropout in the first week were calculated.

\section{Results}

out of the 2050 files, 2003 of data was suitable for analysis. All of the residents were male adults. More than two-thirds of patients were younger than 40 years of age and most of them were singles (64\%), unemployed (68\%), and had intermediate or secondary school education (73\%). Forty-six percent of patients reported Opioids use, $36 \%$ hash, $34 \%$ amphetamine, and $19 \%$ reported alcohol abuse. The retention rate for three months and six months was $45 \%$ and $28 \%$ respectively, and $8.3 \%$ dropped outs in the first week. The median duration of stay was 77 days. Residences in TC 1, TC 2, and TC 4 were less likely to stay for more than three months. Unemployment, and being students was associated with completion of treatment (stay > 6 months), while admission to TC 1 and TC-2 was associated with drop out prior completing the treatment program.

\section{Conclusion}

Three-month retention rates of $45 \%$ in Saudi addiction ATCs is reasonable and consistent with reported rates worldwide. In addition, treatment completion rate and drop out within the first week are at least comparable to the average rates recorded elsewhere. These rates can be considered as indicators for successful Saudi ATCs programs. However, there have been substantial variation between the different Saudi AATCs which may require further exploration to determine the factors related to these disparities.

\section{Introduction:}


Addiction is a complex chronic disorder with frequent relapses affecting physical, psychological, and social health[1]. Long continuous management is required to address various biological, psychological, social, and spiritual needs [2], [3]. Addiction therapeutic community (ATC) is a long term residential treatment model that address these different aspects of patients' needs [4]. It is a drug-free residential treatment facility where 'community as method' is the cornerstone approach [4]-[6]. In this treatment model, addiction is a sign of disorganized personal life management, and stopping drug use is a manifestation of personal recovery that involves other physical, psychosocial, and spiritual aspects [4]. Addiction Therapeutic communities (ATCs) are effective in improving sobriety and reducing drug misuse, unemployment, criminalities, recidivism, relationship conflicts, homelessness, psychiatric comorbidities, drug injections, and drug overdose [7], [8], [17]-[23], [9]-[16]. Furthermore, it has been proven superior to several other types of addiction treatment modalities [16], [23]. Retention for longer duration is a consistent well studied factor that is associated with better ATCs outcomes [6], [8], [12], [13], [24], [25]. It has been noted that residents who have stayed for three months or more in ATCs services have better outcomes than earlier dropping residents, which allowed some studies to consider staying 90 days as a crucial period [6], [26]. The National Institute of Drug Abuse admits that treatment programs that last less than three months may not be successful in achieving intended outcomes [27]. A variety of factors linked to the retention of residents in care have been studied [9], [10], [25]. These factors can be divided into factors related to patient characteristics and factors related to the treatment program and its process [9], [10], [25]. Yong age, unemployment, low education, severe drug use, and previous treatment history are well-known factors associated with early drop out [28]-[32]. In contrast, factors like high education, employment, legal pressure, enhancing resident's motivation, and involvement of the family and social network in treatment are related to resident's retention improvement [22], [33]-[37]. Furthermore, Meier and Best noted that a not too large, well-scheduled treatment program with healthy and not so stressful organized activities with appropriate individual counseling correlate with a high completion rate of treatment program [38]. However, the relationship between treatment retention and drug type, resident's comorbidities, the history of incarceration, race, and gender have often shown conflicting and contradictory results [24], [28]. This paper aims to estimate retention rates in Saudi ATCs and study use patterns and residents' characteristic factors associated with early dropout and long-term retention. Knowing these factors could help recognize those at risk of drop out and those who may complete the program and intervene accordingly.

\section{Methods:}

\section{Population and data source}

The study included records data of all ATCs discharged residents in Saudi Arabia since ATCs establishment until September 2014. The reason for discharge could be related to completing the treatment program, discharge against treatment advice, dismissing from the program due to breaking the roles, or any other cause. We exclude only admissions with missing data due to incomplete records. At the time of study conduction, there were only five addiction ATCs in the Kingdom of Saudi Arabia, and all of them were included. Two of the ATCs were in Dammam city and the others located in Riyadh, Jeddah, 
and Taif cities. Addiction ATCs establishments were recent. First Addiction TC was operated in 2000 and belonged to Alamal complex for mental health in Dammam. However, it takes almost a decade to establish the next addiction ATCs. The other four addiction ATCs operated between 2009 and 2013. Three of these ATCs were governmental, while the other two operated by non-governmental societies [39]. All of them are traditional addiction therapeutic communities with almost similar treatment and rehabilitation program [40]. The usual recommended length of stay is six to nine months. So, those who stayed six months or more were considered to be treatment program completers. All of these ATCs were for males and not accepting age less than twenty nor compulsory admissions.

Two paramedical staff collected data under the author's supervision from the patients' charts and records using comprehensive forms that include demographic information, number of admissions, diagnoses, admissions dates, lengths of stays, and addicted substances. We collected the data between September and January 2015. The author visited each TC, assigned two paramedical staff in each TC, and trained them on collecting data from resident files and records and fill in previously structured forms. We included all files in the study and excluded those with missing admission and discharge dates. The project's ethical approval was issued by the Institutional Review Board of the College of Medicine at AlImam Muhammad Ibn Saud Islamic University HAPO-01-R-010.

\section{Statistical analysis}

Data were recorded into the Microsoft excel sheet and exported into SPSS v21.0 for further analysis. Descriptive statistics used to represent the data. Quantitative variables were expressed as mean, standard deviation, median, and range, while categorical data were expressed as frequency and percentage and analyzed using the Chi-square test. $P$-value $<0.05$ was considered significant, and variables with $p$-value $<0.05$ were entered into multinomial binary logistic regression analysis. Therapeutic communities were labeled by numbers rather than their names for convenience.

\section{Results:}

We collected data of 2003 patients out of 2050 files that were discharged before the end of September 2014. General characteristics of them have been shown in table 1 . All of the residents are adult males since there was no addiction ATCs for females or adolescents in Saudi Arabia at the time of the study. More than two-thirds of patients are younger than 40-year-old. Forty-three percent belonged to therapeutic community number three. The majority were single (64\%), unemployed $(68 \%)$, have intermediate or secondary school education (73\%). Forty-six percent of patients reported Opioids use, $36 \%$ hash, $34 \%$ amphetamine, and 19\% reported alcohol misuse. Most of the patients admitted once (92\%), $6.7 \%$ admitted twice, and only $1.4 \%$ admitted more than two times.

Since the program's minimum duration was six months, $28 \%$ of the patient considered treatment completers. Dropouts in the first week were $8.3 \%$ of all admissions, and almost $45 \%$ stayed for more than three months. The median duration of stay was 77 days. The first-week dropout was associated with age, residency, occupation, and type of drug used. However, all these associations were insignificant when 
adjusting for other factors. Furthermore, Age, residency, employment, social status, and drug users were significantly associated with retention for three months on univariate analysis. Though, these associations were insignificant after multiple regression analyses except residency in TC 1, TC 2, and TC 4, which were less likely to stay for more than three months. After adjusting for other confounders, multivariate regression analysis excluded age and confirm unemployment and students to be associated with treatment completion. On the other hand, Admission to TC 1 and TC-2 prove to be significantly associated with treatment program incompletion. (Table 2, 3 and 4) 


\begin{tabular}{|c|c|c|}
\hline Variable & $\mathrm{n}$ & $\%$ \\
\hline \multicolumn{3}{|l|}{ Age (years) } \\
\hline $20-29$ & 721 & 36 \\
\hline $30-39$ & 723 & 36.1 \\
\hline $40-49$ & 437 & 21.8 \\
\hline$>50$ & 103 & 5.1 \\
\hline \multicolumn{3}{|l|}{ Residency } \\
\hline $\mathrm{TC}^{*} 1$ & 511 & 25.5 \\
\hline TC 2 & 147 & 7.3 \\
\hline TC 3 & 859 & 42.9 \\
\hline TC 4 & 26 & 1.3 \\
\hline TC 5 & 459 & 22.9 \\
\hline \multicolumn{3}{|l|}{ Occupation: } \\
\hline Unemployed & 1259 & 68.4 \\
\hline Student & 48 & 2.6 \\
\hline employed & 517 & 28.1 \\
\hline Retired & 16 & 0.9 \\
\hline \multicolumn{3}{|l|}{ Social status } \\
\hline Single & 1494 & 75.9 \\
\hline Married & 475 & 24.1 \\
\hline \multicolumn{3}{|l|}{ Education: } \\
\hline Illiterate & 20 & 1 \\
\hline Primary & 417 & 21.5 \\
\hline Intermediate & 689 & 35.4 \\
\hline Secondary & 732 & 37.7 \\
\hline
\end{tabular}




\begin{tabular}{|c|c|c|}
\hline University & 86 & 4.4 \\
\hline \multicolumn{3}{|l|}{ Type of drugs used: } \\
\hline Alcohol & 135 & 7 \\
\hline Amphetamine & 223 & 11.5 \\
\hline Hash & 260 & 13.4 \\
\hline Opioid & 723 & 37.2 \\
\hline others(sedatives-cocaine-dextromethorphan) & 9 & 0.5 \\
\hline Amphetamine \& Alcohol & 56 & 2.9 \\
\hline Amphetamine \& Hash & 237 & 12.2 \\
\hline Hash \& Alcohol & 72 & 3.7 \\
\hline Opioid \& Hash & 19 & 1 \\
\hline Multiple (>3drugs) & 207 & 10.7 \\
\hline \multicolumn{3}{|l|}{ Number of admissions: } \\
\hline One & 1839 & 91.9 \\
\hline Two & 126 & 6.7 \\
\hline Three & 14 & 0.8 \\
\hline Four & 9 & 0.4 \\
\hline Five & 3 & 0.1 \\
\hline \multicolumn{3}{|l|}{ Duration of stay: } \\
\hline Median & 77 & \\
\hline 1-7 days & 166 & 8.3 \\
\hline 8-90 days & 933 & 46.6 \\
\hline $91-180$ days & 345 & 17.2 \\
\hline more than 180 days & 558 & 27.9 \\
\hline
\end{tabular}


Table 1: Factors associated with retentions and dropout

\begin{tabular}{|c|c|c|c|c|c|c|}
\hline \multirow[t]{2}{*}{ Variable } & $\begin{array}{l}\text { First } \\
\text { week } \\
\text { Dropout }\end{array}$ & P.value & $\begin{array}{l}\text { Three } \\
\text { months } \\
\text { Retention }\end{array}$ & P.value & $\begin{array}{l}\text { Six } \\
\text { months } \\
\text { Retention }\end{array}$ & P.value \\
\hline & $\mathrm{n}(\%)$ & & n (\%) & & n (\%) & \\
\hline $\begin{array}{l}\text { Age } \\
\text { (years): }\end{array}$ & & 0.279 & & 0.001 & & 0.000 \\
\hline $20-29$ & $61(8)$ & & $287(40)$ & & $177(25)$ & \\
\hline $30-39$ & $71(10)$ & & $327(45)$ & & $184(25)$ & \\
\hline $40-49$ & $25(6)$ & & $225(51)$ & & $151(35)$ & \\
\hline \multirow[t]{2}{*}{$>50$} & $8(8)$ & & $57(55)$ & & $43(42)$ & \\
\hline & & 0.000 & & 0.001 & & 0.000 \\
\hline \multicolumn{7}{|l|}{ Residency: } \\
\hline TC 1* & $53(10)$ & & $268(52)$ & & $184(36)$ & \\
\hline TC 2 & $7(5)$ & & $94(64)$ & & $62(42)$ & \\
\hline TC 3 & $35(4)$ & & $340(40)$ & & $214(25)$ & \\
\hline TC 4 & $51(9)$ & & $17(65)$ & & $3(12)$ & \\
\hline TC 5 & $66(14)$ & & $184(40)$ & & $95(21)$ & \\
\hline & & 0.258 & & 0.02 & & 0.009 \\
\hline \multicolumn{7}{|l|}{ Occupation: } \\
\hline Unemployed & $89(7)$ & & $557(44)$ & & $184(36)$ & \\
\hline Student & $3(6)$ & & $17(35)$ & & $62(42)$ & \\
\hline employed & $48(9)$ & & $263(51)$ & & $214(25)$ & \\
\hline Retired & $0(0)$ & & $8(50)$ & & $3(12)$ & \\
\hline Social status: & & 0.032 & & 0.067 & & 0.175 \\
\hline Single & 111(7) & & $659(44)$ & & $405(27)$ & \\
\hline Married & $50(11)$ & & $227(48)$ & & $144(30)$ & \\
\hline Education: & & 0.88 & $5(25)$ & 0.481 & & 0.455 \\
\hline Illiterate & $1(5)$ & & $187(45)$ & & $3(15)$ & \\
\hline Primary & $35(8)$ & & $317(46)$ & & 111 (27) & \\
\hline
\end{tabular}




\begin{tabular}{|c|c|c|c|c|c|c|}
\hline Intermediate & $54(8)$ & & $346(47)$ & & $206(30)$ & \\
\hline Secondary & $56(8)$ & & $37(43)$ & & $213(29)$ & \\
\hline University & $9(10)$ & & & & $22(26)$ & \\
\hline Type of drugs used: & & 0.782 & & 0.039 & & 0.031 \\
\hline Alcohol & $10(7)$ & & $51(38)$ & & $30(22)$ & \\
\hline Amphetamine & $18(8)$ & & $106(4)$ & & $64(29)$ & \\
\hline Hash & $27(10)$ & & $109(42)$ & & $58(22)$ & \\
\hline Opioid & $48(7)$ & & $359(50)$ & & $230(32)$ & \\
\hline $\begin{array}{l}\text { others(sedatives-cocaine- } \\
\text { dextromethorphan) }\end{array}$ & $1(11)$ & & $4(44)$ & & $2(22)$ & \\
\hline Amphetamine \& Alcohol & $5(9)$ & & $25(45)$ & & $17(30)$ & \\
\hline Amphetamine- Hash & $18(8)$ & & $88(37)$ & & $54(23)$ & \\
\hline Hash \& Alcohol & $6(8)$ & & $29(40)$ & & $18(25)$ & \\
\hline Opioid \& Hash & $2(11)$ & & $8(42)$ & & $4(21)$ & \\
\hline Multiple (>3drugs) & $21(10)$ & & $105(51)$ & & $68(33)$ & \\
\hline Number of admissions: & & 0.741 & & 0.177 & & 0.206 \\
\hline One & $155(8)$ & & $839(46)$ & & $524(46)$ & \\
\hline Two & $9(7)$ & & $52(39)$ & & $27(47)$ & \\
\hline Three & $2(13)$ & & $8(50)$ & & $5(48)$ & \\
\hline Four & $0(0)$ & & $4(44)$ & & $2(49)$ & \\
\hline Five & $0(0)$ & & $0(0)$ & & $0(50)$ & \\
\hline TC: Therapeutic communit & & & & & & \\
\hline
\end{tabular}


all Table 3: Multiple regression of all predictors of First week dropouts and Three months retention with $\mathrm{P}<0.05$ on univariate analyses

First week dropouts B $\begin{aligned} & \text { Std. Wald df } \begin{array}{l}\text { Odds ratio } \\ \text { Error }\end{array} \\ & (95 \% \mathrm{Cl})\end{aligned}$ P. value

Residency

TC 1 $\begin{array}{llll}.332 & .203 & 2.674 & 1\end{array}$ $1.393(.936-$ .102 2.073)

TC 2

$\begin{array}{lllll}1.139 & .414 & 7.552 & 1 & 3.122 \\ & & & (1.386- \\ & & & 7.032)\end{array}$

TC 3

$\begin{array}{llll}1.309 & .225 & 33.874 & 1\end{array}$

3.703

(2.383-

.000

5.755)

TC 4

$\begin{array}{llll}-.439 & .523 & .705 & 1\end{array}$

$.645(.232-$

.401 1.796)

TC 5

Three months retention

[ Age category]

$0^{*}$

[ Age category]

B Std. Wald df Error .434 .577

$.565 \quad 1$

1
$1.543(.498-$
$4.780)$

Residency

TC 1

$\begin{array}{llll}-.620 & .168 & 13.698 & 1\end{array}$

.538

(.387-.747)

.000

TC 2

$-.959 \quad .219$

$19.185 \quad 1$

.383

(.249-.589)

.000

TC 3

.031

.144

.047

$1.032(.779-$ 1.367)

.829

TC 4

$-1.042$

.439

5.638

.353

(.149-.834)

.018

TC 5

Type of drug used

Alcohol

$$
413
$$

Amphetamine

$0^{*}$

Hash

Opioid

$\begin{array}{llllll}.413 & .246 & 2.816 & 1 & 1.512(.933- & \\ & & & & 2.450) & \\ & & & \end{array}$

$\begin{array}{lll}-.123 & .218 \quad .315\end{array}$

0




\begin{tabular}{|c|c|c|c|c|c|c|}
\hline & & & \multicolumn{4}{|c|}{$1.299)$} \\
\hline $\begin{array}{l}\text { others(sedatives-cocaine- } \\
\text { dextromethorphan) }\end{array}$ & -.139 & .759 & .034 & 1 & $\begin{array}{l}.870(.197- \\
3.849)\end{array}$ & .855 \\
\hline Amphetamine \& Alcohol & -.071 & .330 & .047 & 1 & $\begin{array}{l}.931(.488- \\
1.776)\end{array}$ & .828 \\
\hline Amphetamine \& Hash & .256 & .214 & 1.423 & 1 & $\begin{array}{l}1.292(.848- \\
1.966)\end{array}$ & .233 \\
\hline Hash \& Alcohol & .170 & .294 & .336 & 1 & $\begin{array}{l}1.186(.666- \\
2.109)\end{array}$ & .562 \\
\hline Opioid \& Hash & .210 & .549 & .146 & 1 & $\begin{array}{l}1.233(.420- \\
3.618\end{array}$ & .703 \\
\hline Multiple (>3drugs) & $0^{*}$ & . & & 0 & . & . \\
\hline $\begin{array}{l}\text { * TC: Therapeutic commur } \\
\text { parameter is set to zero be }\end{array}$ & 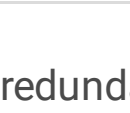 & & & & & This \\
\hline
\end{tabular}


Table 4: Multiple regression of all predictors of Six months retention with $\mathrm{P}<0.05$ on univariate analyses

\begin{tabular}{|c|c|c|c|c|c|c|}
\hline Six months Retention & B & $\begin{array}{l}\text { Std. } \\
\text { Error }\end{array}$ & Wald & $d f$ & $\begin{array}{l}\text { Odds ratio } \\
(95 \% \mathrm{Cl})\end{array}$ & $\begin{array}{l}\mathrm{P} . \\
\text { value }\end{array}$ \\
\hline [Age category ] & 1.126 & .695 & 2.625 & 1 & $\begin{array}{l}3.083(.790- \\
12.040)\end{array}$ & .105 \\
\hline \multicolumn{7}{|l|}{ Residency } \\
\hline TC 1 & -.709 & .184 & 14.929 & 1 & $\begin{array}{l}.492 \\
(.343-.705)\end{array}$ & .000 \\
\hline TC 2 & -.806 & .227 & 12.607 & 1 & $\begin{array}{l}.447 \\
(.286-.697)\end{array}$ & .000 \\
\hline TC 3 & -.013 & .162 & .007 & 1 & $\begin{array}{l}.987(.718- \\
1.357)\end{array}$ & .934 \\
\hline TC 4 & .872 & .640 & 1.854 & 1 & $\begin{array}{l}2.391(.682- \\
8.388)\end{array}$ & .173 \\
\hline TC 5 & $0^{\star *}$ & . & . & 0 & . & . \\
\hline
\end{tabular}

Occupation

Unemployed

$\begin{array}{lllll}.492 \quad .634 & .604 & 1 & 1.636 \\ & & & & 5.665)\end{array}$

.437

Student

$\begin{array}{lllll}1.675 & .795 & 4.440 & 1 & 5.338\end{array}$

$(1.124-.352)$

employed

$.186 \quad .638$

.085

$1 \quad 1.205(.345-$

.770

Retired

$0^{\star *}$

Type of drug used:

\begin{tabular}{|c|c|c|c|c|c|c|}
\hline Alcohol & .413 & .246 & 2.816 & 1 & $\begin{array}{l}1.441(.845- \\
2.459)\end{array}$ & .180 \\
\hline Amphetamine & -.123 & .218 & .315 & 1 & $\begin{array}{l}.796(.502- \\
1.263)\end{array}$ & .333 \\
\hline Hash & .110 & .206 & .284 & 1 & $\begin{array}{l}1.105(.707- \\
1.727)\end{array}$ & .661 \\
\hline Opioid & -.099 & .184 & .289 & 1 & $\begin{array}{l}.881(.598- \\
1.298)\end{array}$ & .522 \\
\hline $\begin{array}{l}\text { others(sedatives-cocaine- } \\
\text { dextromethorphan) }\end{array}$ & -.139 & .759 & .034 & 1 & $\begin{array}{l}.859(.158- \\
4.658)\end{array}$ & .860 \\
\hline Amphetamine \& Alcohol & -.071 & .330 & .047 & 1 & $\begin{array}{l}.682(.344- \\
1.353)\end{array}$ & .274 \\
\hline
\end{tabular}




\begin{tabular}{|c|c|c|c|c|c|c|}
\hline Amphetamine \& Hash & .256 & .214 & 1.423 & 1 & $\begin{array}{l}1.093(.688- \\
1.738)\end{array}$ & .706 \\
\hline Hash \& Alcohol & .170 & .294 & .336 & 1 & $\begin{array}{l}1.017(.540- \\
1.918)\end{array}$ & .957 \\
\hline Opioid \& Hash & .210 & .549 & .146 & 1 & $\begin{array}{l}1.028(.309- \\
3.422)\end{array}$ & .964 \\
\hline Multiple (>3drugs) & $0^{\star \star}$ & & & 0 & & . \\
\hline
\end{tabular}

\section{Discussion:}

Three-month retention rates of $45 \%$ in Saudi addiction ATCs are acceptable and match with the documented rates worldwide and consistent with previous [13], [24], [41]. Most studies of long-term addiction therapeutic communities reported a three-month retention rate between $30 \%$ and $50 \%$ [41]. Gossip and his colleagues studied retention rates in eleven long-term residential programs in England and reported a $40 \%$ retention rate for the same period. In some other studies, the retention rate for three months was $25 \%, 31 \%$, and $32 \%$ among intravenous drug injectors [42], amphetamine users, and all other drug users, respectively [43]. On the contrary, Mulder et al. reported a rate of 57\%; however, the study population was small in size, and $71 \%$ of them were come to treatment due to court orders and not on their free well as in our study population [35]. Furthermore, the program completion rate was $28 \%$, which lay in the middle of other studies, 9-56\% range [10].

Fortunately, our study population is more or less similar in age, employment, gender, and marital status to those mentioned earlier. Most of the drugs used are opioids, as in not a little of them [13], [26]. The median of stay was 77 days compared to 70 days reported in English long-term residential treatment facilities [13] and 39 days in a prospective Australian study [24] . Although Saudi ATCs followed the same program structure and showed no differences in essential ATCs treatment elements [40], there were significant differences in retention rate, which need to be explored.

Being a student associated with treatment completion while the residency site was found to drop out before completing the program. Interestingly, the type of drug used was not associated with dropout and retention at one week, three months, or six months matching with other studies findings [30], [35]. This may stress the addiction therapeutic community view of addiction as an illness of the person rather than the drug itself [4].

The first-week dropout was $8.3 \%$, which is better than most similar studies where dropout may exceed $17 \%$ to $20 \%$, although high dropout makes these few days critical, requiring more intentions and a specially tailored approach. As in other periods, the site of residency is associated with dropout in the first week, which means different approaches or applications in dealing with that among the different ATCs. 


\section{Conclusion:}

Reported retention and dropout rates are good indicators for the effectiveness of Saudi ATCs. However, non-addiction specialized people may consider these numbers as humble ones due to their lack of experience about the nature of addiction disorder and about ATCs, which deals with the most severe cases. Performances of the five ATCs were not the same though they apply the same program concepts and tools. These significant rates differences may need further study to explore and determine the factors that may play roles in this gap.

\section{Declarations:}

*The project's ethical approval was issued by the Institutional Review Board of the College of Medicine at Al-Imam Muhammad Ibn Saud Islamic University HAPO-01-R-010.

*Availability of data and material: available upon request

* Competing interest: Author has no conflict of interests, and the work was not supported or funded by any drug company.

* Funding: No funding

* Authors' contributions: NA

* Acknowledgements: NA

\section{References}

[1] A. T. McLellan, "Have we evaluated addiction treatment correctly? Implications from a chronic care perspective," Addiction, vol. 97, no. 3, pp. 249-252, 2002.

[2] A. T. McLellan, J. R. McKay, R. Forman, J. Cacciola, and J. Kemp, "Reconsidering the evaluation of addiction treatment: from retrospective follow-up to concurrent recovery monitoring," Addiction, vol. 100, no. 4, pp. 447-458, 2005.

[3] W. White, Recovery management and recovery-oriented systems of care, vol. 6. Chicago: Great Lakes Addiction Technology Transfer Center, Northeast ..., 2008.

[4] G. De Leon, The therapeutic community: Theory, model, and method. Springer Publishing Company, 2000.

[5] G. Adshead, "Security and the social mind: Attachment and therapeutic communities," Ther. Communities Int. J. Ther. Communities, 2015. 
[6] D. Veale, P. Gilbert, J. Wheatley, and I. Naismith, "A new therapeutic community: Development of a compassion-focussed and contextual behavioural environment," Clin. Psychol. Psychother., vol. 22, no. 4, pp. 285-303, 2015.

[7] L. Magor-blatch, N. Bhullar, B. Thomson, and E. Thorsteinsson, "A systematic review of studies examining effectiveness of therapeutic communities," 2014.

[8] P. K. Staiger, P. Liknaitzky, A. J. Lake, and S. Gruenert, "Longitudinal Substance Use and Biopsychosocial Outcomes Following Therapeutic Community Treatment for Substance Dependence," J. Clin. Med., vol. 9, no. 1, p. 118, 2020.

[9] W. Vanderplasschen et al., "Therapeutic communities for addictions: a review of their effectiveness from a recovery- oriented perspective (Greek version ). Therapeutic Communities for Addictions: A Review of Their Effectiveness from a Recovery-Oriented Perspective," no. September 2016, 2014.

[10] M. Malivert, “Effectiveness of Therapeutic Communities:," pp. 1-11, 2012.

[11] R. M. Etheridge, S. G. Craddock, G. H. Dunteman, and R. L. Hubbard, "Treatment services in two national studies of community-based drug abuse treatment programs," J. Subst. Abuse, vol. 7, no. 1, pp. 9-26, 1995.

[12] M. Gossop, J. Marsden, D. Stewart, and A. Rolfe, "Treatment retention and 1 year outcomes for residential programmes in England,” vol. 57, pp. 89-98, 1999.

[13] D. D. Simpson and S. B. Sells, "Effectiveness of treatment for drug abuse: An overview of the DARP research program," Adv. Alcohol Subst. Abuse, vol. 2, no. 1, pp. 7-29, 1982.

[14] A. Jones et al., "The Drug Treatment Outcomes Research Study (DTORS): Final outcomes report," Londres Home Off. Recuper. http//www. dtors. org. uk/reports/DTORS_Final_Main. pdf, 2009.

[15] J. R. McKay, "Continuing care research: What we have learned and where we are going," J. Subst. Abuse Treat., vol. 36, no. 2, pp. 131-145, 2009.

[16] Y.-I. Hser, M. D. Anglin, and B. Fletcher, “Comparative treatment effectiveness: Effects of program modality and client drug dependence history on drug use reduction," J. Subst. Abuse Treat., vol. 15, no. 6, pp. 513-523, 1998.

[17] R. L. Hubbard, J. V Rachal, and S. G. Craddock, "Treatment outcome prospective study (TOPS): client characteristics before, during, and after treatment" Washingt. NIDA, 1984.

[18] S. Darke, J. Ross, K. L. Mills, A. Williamson, A. Havard, and M. Teesson, "Patterns of sustained heroin abstinence amongst long-term, dependent heroin users: 36 months findings from the Australian Treatment Outcome Study (ATOS)," Addict. Behav., vol. 32, no. 9, pp. 1897-1906, 2007. 
[19] B. J. Rounsaville, M. M. Weissman, K. Crits-Christoph, C. Wilber, and H. Kleber, “Diagnosis and symptoms of depression in opiate addicts: Course and relationship to treatment outcome," Arch. Gen. Psychiatry, vol. 39, no. 2, pp. 151-156, 1982.

[20] R. P. Mattick, S. O'Brien, and J. Dodding, Outcome evaluation of the Woolshed Program. National Drug and Alcohol Research Centre, University of New South Wales, 1998.

[21] R. H. Coombs, "Back on the streets: Therapeutic communities' impact upon drug users," Am. J. Drug Alcohol Abuse, vol. 8, no. 2, pp. 185-201, 1981.

[22] M. L. Hiller, K. Knight, and D. D. Simpson, "Prison-based substance abuse treatment, residential aftercare and recidivism," Addiction, vol. 94, no. 6, pp. 833-842, 1999.

[23] N. Vidjak, "Treating heroin addiction: Comparison of methadone therapy, hospital therapy without methadone, and therapeutic community," Croat. Med. J., vol. 44, no. 1, pp. 59-64, 2002.

[24] S. Darke, G. Campbell, and G. Popple, "Retention, early dropout and treatment completion among therapeutic community admissions," Drug Alcohol Rev., vol. 31, no. 1, pp. 64-71, 2012.

[25] C. Perryman, G. A. Dingle, C. Perryman, and G. Dingle, "A systematic review of the methodologies used in research related to adult drug and alcohol rehabilitation in therapeutic communities," no. September 2016, 2015.

[26] D. D. Simpson, G. W. Joe, K. M. Broome, M. L. Hiller, K. Knight, and G. A. Rowan-Szal, “Program diversity and treatment retention rates in the Drug Abuse Treatment Outcome Study (DATOS).," Psychol. Addict. Behav., vol. 11, no. 4, p. 279, 1997.

[27] N. D. Volkow, Principles of drug addiction treatment: $A$ research-based guide, vol. 12, no. 4180. DIANE Publishing, 2011.

[28] J. J. López-goñi, J. Fernández-, C. Illescas, and N. Landa, “Determining socio-demographic predictors of treatment dropout: results in a therapeutic community," no. 2006, pp. 374-378, 2008.

[29] K. J. Brower, F. C. Blow, E. M. Hill, and S. A. Mudd, "Treatment outcome of alcoholics with and without cocaine disorders," Alcohol. Clin. Exp. Res., vol. 18, no. 3, pp. 734-739, 1994.

[30] R. E. Claus, L. R. Kindleberger, and M. C. Dugan, "Predictors of attrition in a longitudinal study of substance abusers," J. Psychoactive Drugs, vol. 34, no. 1, pp. 69-74, 2002.

[31] R. R. Gainey, E. A. Wells, J. D. Hawkins, and R. F. Catalano, "Predicting treatment retention among cocaine users," Int. J. Addict., vol. 28, no. 6, pp. 487-505, 1993.

[32] J. R. McKAY, A. T. McLELLAN, A. I. Alterman, J. S. Cacciola, M. J. Rutherford, and C. P. O’Brien, "Predictors of participation in aftercare sessions and self-help groups following completion of intensive 
outpatient treatment for substance abuse.," J. Stud. Alcohol, vol. 59, no. 2, pp. 152-162, 1998.

[33] N. Sadir, M. Shojaei, K. Moadab, R. Abbasi, and A. Bahrampour, "Outcome Evaluation of Therapeutic Community Model in Iran," vol. 1, no. 2, pp. 131-135, 2013.

[34] W. N. Welsh and P. N. McGrain, "Predictors of therapeutic engagement in prison-based drug treatment," Drug Alcohol Depend., vol. 96, no. 3, pp. 271-280, 2008.

[35] R. T. Mulder, C. M. A. FRAMPTON, H. Peka, G. Hampton, and T. Marsters, "Predictors of 3-month retention in a drug treatment therapeutic community," Drug Alcohol Rev., vol. 28, no. 4, pp. 366-371, 2009.

[36] K. Knight, M. L. Hiller, K. M. Broome, and D. D. Simpson, "Legal pressure, treatment readiness, and engagement in long-term residential programs," J. Offender Rehabil., vol. 31, no. 1-2, pp. 101-115, 2000.

[37] M. L. Hiller, K. Knight, C. Leukefeld, and D. D. Simpson, "Motivation as a predictor of therapeutic engagement in mandated residential substance abuse treatment," Crim. Justice Behav., vol. 29, no. 1, pp. 56-75, 2002.

[38] P. S. Meier and D. Best, "Programme factors that influence completion of residential treatment," no. July, pp. 349-355, 2006.

[39] A. T. Alshomrani, A. T. Khoja, S. F. Alseraihah, and M. A. Mahmoud, "Drug use patterns and demographic correlations of residents of Saudi therapeutic communities for addiction," J. Taibah Univ. Med. Sci., vol. 12, no. 4, pp. 304-312, 2017.

[40] A. T. Alshomrani, "Saudi addiction therapeutic communities: Are they implementing the essential elements of addiction therapeutic communities?," Neurosciences, vol. 21, no. 3, pp. 227-231, 2016.

[41] P. B. Practice, "Towards Better Practice in Therapeutic Communities[1] P. B. Practice, 'Towards Better Practice in Therapeutic Communities."'

[42] J. Keen, P. Oliver, G. Rowse, and N. Mathers, "Residential rehabilitation for drug users: a review of 13 months' intake to a therapeutic community," Fam. Pract., vol. 18, no. 5, pp. 545-548, 2001.

[43] M. Maglione, B. Chao, and D. Anglin, "Residential treatment of methamphetamine users: Correlates of drop-out from the California Alcohol and Drug Data System (CADDS), 1994-1997," Addict. Res., vol. 8 , no. 1, pp. 65-79, 2000. 